\title{
Fungal microflora in dried persimmon fruits
}

\author{
G.T. Gündüz, A. Korkmaz, Z. Öztürk and I. Emenli \\ Food Engineering Department, Faculty of Engineering, Ege University, Izmir, Turkey
}

Corresponding Author: G.T. Gündüz, gulten.tiryaki.gunduz@ege.edu.tr

Received: 30 September 2018 / Accepted: 25 November 2019 / Published: 13 January 2020

(c) 2020 Codon Publications

OPEN ACCESS CC) (i) (9)

RESEARCH ARTICLE

\begin{abstract}
Persimmon fruit due to its short shelf life is often consumed as fresh during the season, but it is also consumed as a dried fruit. In recent years, dried persimmon fruits with mouldy appearance as a whole are sold by small-scale local enterprises. In this study, the fungal profile of both fruit surface and inner parts of the whole dried persimmon fruit was investigated. Mould and yeast counts and osmophilic count were determined by using acidified potato dextrose agar and malt extract agar containing $40 \%$ sucrose respectively. Mould isolates were identified considering their cultural and morphological properties. Two different sampling methods were applied and no significant differences were found for osmophilic yeast counts, yeast counts and mould counts except osmophilic mould counts. In this study, it was observed that $95 \%$ of the samples were contaminated with moulds and the number of moulds was in the range of $<1-4.34 \log$ colony forming units per gram (cfu/g). Seventeen different genera of moulds were isolated from dried persimmon fruits, and the dominant microflora of the analysed samples were Rhizopus spp., Penicillium spp. and Aspergillus spp.
\end{abstract}

Keywords: dried persimmon fruit; fungal microflora; osmophilic yeast

\section{Introduction}

Persimmon fruit (Diospyros kaki L.) has a tough, glossy, orange-reddish skin and a sweet, juicy and yellow-orange flesh when ripe (Tous and Ferguson, 1996). Persimmon is cultivated in warm regions of the world, such as China, Japan and Korea, but is also gaining popularity in the Mediterranean countries such as Turkey (Akbulut et al., 2008; Nicoleti et al., 2007; Plaza et al., 2012). Persimmon fruit is rich in nutrients such as vitamin $C(0.7 \mathrm{mg} / \mathrm{g}$ of pulp $)$ and pro-vitamin A ( $0.65 \mathrm{mg} / \mathrm{g}$ of pulp), and is a good source of calcium ( $0.09 \mathrm{mg} / \mathrm{g}$ of pulp) and iron (0.002 mg/g of pulp) (Tous and Furguson, 1996). Furthermore, the fruit is a good source of carotenoids, which may have a role in cancer prevention by acting as free radical scavengers or antioxidants (Tee, 1992), in preventing cardiovascular diseases (Gaziona and Hennekens, 1993) and in treating chronic diseases such as photosensitivity diseases (Matthews-Roth, 1993).

Persimmon fruit is generally cultivated in two varieties: astringent and non-astringent. The heart-shaped Hachiya is the most common variety of astringent persimmon. Non-astringent persimmon is consumed as a hard fruit, but it remains edible when it becomes soft.Astringent persimmon contains high levels of soluble tannins and is unpalatably astringent if eaten before it is completely softened (Akbulut et al., 2008). Persimmon fruit reaches its best quality at the end of pre-climacteric stage when it has maximum sugar content and an appealing orange colour. However, as soon as climacteric stage starts, the fruit softens rapidly within a couple of days (Harima et al., 2003). The shelf life of persimmon fruit is extended and its industrial exploitation increases by producing dried persimmon fruits. Drying process improves fruit's shelf life and reduces physiological, microbial and enzymatic degradation (Gardeli et al., 2009). In recent years, dehydrated fruit and pulp have received attention because of certain advantages. The dehydrated fruit is easily obtainable, retains its natural characteristics, has reduced transportation cost, and is safe due to its appropriate moisture level required to prevent the growth of mould, which deteriorates freshness of fruits (Marques et al., 2006). The drying process reduces costs of packaging, storage and transportation because of loss of weight and volume and easiness of handling and further processing (Chauhan and Srivastava, 2009; Duan et al., 2010). 
There are several factors such as the nature of food, drying method, drying conditions and pre-treatment prior to drying, which affect the quality of dried products (Rahman et al., 2009; Sablani, 2006). Microbial growth is prevented or retarded in dried products if a sufficient number of pathogenic microorganisms are present after the drying process, but this may pose threat to consumers. Microbial growth is inhibited once the product is in a desiccated state, but vegetative cells and spores can remain viable for months (Beuchat et al., 2013; Bourdoux et al., 2016). Moulds are common contaminants of agricultural products. Mould contamination in food not only results in spoilage or economic losses but is a serious concern for human and animal health since it may produce toxic metabolites called mycotoxins (Park et al., 2003). Mycotoxin formation can take place at any of the stages of growing, harvesting, transporting, drying and during the storage of dried fruit and vegetable products. Natural occurrence of mycotoxins and fungal contamination of dried fruits have been investigated in many countries by different authors (Aksoy et al., 2007; Battilani et al., 2003; Bayman et al., 2002; Herry and Lemetayer, 1992; MacDonald et al., 1999; Meyvaci et al., 2005; Möller and Nyberg, 2003; Zohri and Abdel-Gawad, 1993). Persimmon fruits are dried mostly using sundrying method; thus, there are major concerns regarding potential mixing of foreign substances, colour changes, mould growth and other damages during the drying process (Choi et al., 2017). As dry fruit is normally consumed directly, there is a need to verify the microbiological quality of these products (Iamanaka et al., 2007). The objective of this study is to determine mould and yeast counts in dried persimmon fruits and to identify fungal microflora in these sold as a whole in markets.

\section{Materials and methods}

\section{Preparation of samples}

In this study, 40 different samples of dried whole persimmons were purchased in their original intact packets from market and small-scale local enterprises in İzmir, Turkey, and analysed for fungal contamination. Each sample contains 5-6 dried whole persimmons. Two sampling methods were used for preparing dilution for microbiological counts. In the first sampling method (rinse method), three dried whole persimmon fruits $(60-70 \mathrm{~g})$ from each part were aseptically placed in a stomacher bag containing 100-ml diluent and shaken for $1 \mathrm{~min}$. In the second sampling method (homogenisation method), 10-g samples were taken from the external surfaces of dried persimmon fruits. These samples were homogenised with a stomacher for $1 \mathrm{~min}$ after addition of 90-ml diluent. For both methods, appropriate decimal dilutions were prepared by using $0.1 \%$ peptone water (PW, $\mathrm{pH}$ $7.0-7.4)$ and $20 \%$ sucrose solution (1:10) for mould--yeast counts and osmophilic counts respectively.

\section{Yeast and mould counts}

Yeast and mould counts were done by plating of dilutions to acidified potato dextrose agar (PDA, Oxoid, $\mathrm{pH}$ 5.4-5.8). All plates were incubated at $25{ }^{\circ} \mathrm{C}$ for 3-5 days. At the end of the incubation period, mould and yeast counts were done separately and results were expressed as colony forming units per gram (cfu/g) or colony forming units per fruit (cfu/fruit) for homogenisation and rinse methods respectively.

\section{Osmophilic count}

Malt Extract Agar (MEA, Merck, pH 5.4-5.8) containing $40 \%$ sucrose was used to determine osmophilic mould and yeast counts. After the inoculation of plates using pour plate technique, they were incubated at 25 ${ }^{\circ} \mathrm{C}$ for $3-5$ days. At the end of incubation period, mould and yeast colonies were counted separately (Pitt and Hocking, 2009).

\section{Identification of moulds}

Mould identification was performed according to the identification keys provided in Pitt and Hocking (2009). Moulds grown on incubated plates were isolated and purified on slant PDA and further sub-cultured for microscopic observation and identification. Ninety-two mould isolates were selected from different colonies on petri dishes using a stereoscopic microscope (Olympus SZ61, Tokyo, Japan). Selected mould isolates were inoculated with a single culture at three points on Czapek yeast extract agar (CYA), malt extract agar (MEA) and 25\% glycerol nitrate agar (G25N). Plates were incubated at $25^{\circ} \mathrm{C}$ for 7 days and colonies were identified up to genus level according to the methods described in Pitt and Hocking (2009). Colony size, density, colouration, production of aerial mycelia and conidia, and surface and reverse colony pigmentation were examined with this method (Skaar and Stenwig, 1996).

\section{Preparation of fungal slide cultures}

Fungal slide cultures of selected mould isolates were prepared to determine morphological characteristics microscopically. For the preparation of slide cultures, melted PDA media of about $0.1 \mathrm{ml}$ dropped onto sterile glass slide and each fungal isolate to be identified was inoculated onto edges of this solidified agar. After that, a sterile cover slip was placed to the top of solidified agar containing inoculated mold. The prepared slide culture was placed into a sterile Petri dish containing moistened cotton plugs in order to maintain required humidity. Plates were incubated at $25{ }^{\circ} \mathrm{C}$ for 7 days. Moulds grown on glass slides were examined microscopically. The fungal slide cultures were prepared to 
observe the microscopic morphology more clearly (Prakash and Bhargava, 2016).

\section{Statistical analyses}

Differences between total mould and yeast counts were analysed by paired sample $t$-test and two independent samples $t$-test using IBM SPSS 20 Statistical Package; statistical significance was defined as $P<0.05$. The Error bars in the given figures correspond to mean standard errors.

\section{Results and discussion}

The results of the analysis done by homogenisation and rinse methods are given in Tables 1 and 2 respectively. In the homogenisation method, the total number of mould and yeast on dried persimmons ranged from $<1$ to $>5.48$ $\log \mathrm{cfu} / \mathrm{g}$, and $95 \%$ of dried persimmon fruits showed mould and yeast contamination. According to the microbiological criteria recommended for dried or frozen fruits, the maximum limit of mould and yeast is $4-5 \log \mathrm{cfu} / \mathrm{g}$ (Turkish Food Codex, 2011). In the present study, of the 40 dried persimmon fruit samples taken, one (2.5\%) was found above M-value (number of microorganisms separating marginally acceptable quality from unacceptable quality), four samples $(10 \%)$ were found between $\mathrm{m}$ and $\mathrm{M}$ values, and the values of other $35(87.5 \%)$ samples were smaller than the m-value (number of microorganisms separating good quality from marginally acceptable quality). The results showed that $12.5 \%$ of dried persimmon fruits were potential health hazard because of mould and yeasts. There are very limited data available on the microbiological quality of dried persimmon fruits. In the present study, moulds were dominant microflora of dried persimmon fruits as $90 \%$ of the samples were contaminated with moulds. On the other hand, yeast count was below the detection limit of $<1.0 \log \mathrm{cfu} / \mathrm{g}$ in $45 \%$ of the samples. In only one sample, yeast count was found above $5.48 \mathrm{log} \mathrm{cfu} / \mathrm{g}$. In comparison to the results obtained in this study, Park et al. (2003) obtained lower levels of mould count in dried persimmon fruits that ranged between 2.0 and $3.26 \mathrm{log} \mathrm{cfu} / \mathrm{g}$.

Dried fruits with low water activity and high sugar content are favourable medium for xerotolerant moulds. In the homogenisation method, osmophilic yeast count and osmophilic mould count were about the same or higher than yeast and mould counts in $75 \%$ and $70 \%$ of the samples respectively. Total osmophilic mould and yeast counts were significantly higher than the total mould and yeast counts by using homogenisation method $(P<0.05)$. On the other hand, no significant differences were found by using the rinse method $(P>0.05)$.

In the rinse method determining microflora on fruit surfaces, the mould and yeast counts were in the range of $<1.52$ to $>7.0 \log \mathrm{cfu} /$ fruit. Total mould and yeast counts were below the detection limit of $1.52 \log \mathrm{cfu} /$ fruit in

Table 1. Frequency of yeast and mould count per gram of dried persimmon fruits (homogenisation method).

\begin{tabular}{|c|c|c|c|c|c|c|}
\hline \multirow[t]{2}{*}{ Fungi } & \multirow[t]{2}{*}{ Range (log cfu/g) } & \multicolumn{5}{|c|}{ No. of samples in the indicated interval (log cfu/g) } \\
\hline & & $<2$ & $2-3$ & $3-4$ & $4-5$ & $>5$ \\
\hline Mould and yeast count & $<1->5.48$ & 12 & 17 & 7 & 3 & 1 \\
\hline Mould count & $<1-4.34$ & 17 & 17 & 5 & 1 & - \\
\hline Yeasts count & $<1->5.48$ & 21 & 12 & 5 & 1 & 1 \\
\hline Osmophilic count & $<1->5.48$ & 8 & 14 & 16 & 1 & 1 \\
\hline Osmophilic mould count & $<1-3.81$ & 14 & 18 & 8 & - & - \\
\hline Osmophilic yeast count & $<1->5.48$ & 21 & 7 & 10 & 1 & 1 \\
\hline
\end{tabular}

Table 2. Frequency of yeast and mould count on the surface of dried persimmon fruits (rinse method).

\begin{tabular}{lcrcccc} 
Fungi & Range (log cfu/fruit) & \multicolumn{5}{c}{ No. of samples in the indicated interval (log cfu/fruit) } \\
\cline { 3 - 6 } & & $<2$ & $\mathbf{2}-3$ & $\mathbf{3 - 4}$ & $\mathbf{4}-\mathbf{5}$ & $>\mathbf{5}$ \\
\hline Mould and yeast count & $<1.52->7.00$ & 8 & 5 & 15 & 8 & 4 \\
Mould count & $<1.52-6.15$ & 9 & 8 & 15 & 7 & 1 \\
Yeast count & $<1.52->7.00$ & 18 & 5 & 10 & 4 & 3 \\
Osmophilic count & $<1.52->7.00$ & 7 & 6 & 13 & 5 & 4 \\
Osmophilic mould count & $<1.52-5.85$ & 10 & 8 & 9 & 6 & 2 \\
Osmophilic yeast count & $<1.52->7.00$ & 19 & 4 & & & 2 \\
\hline
\end{tabular}


eight samples. The mould and yeast counts were above $4 \log \mathrm{cfu} /$ fruit in 12 of the 40 samples. Yeast count was below the detection limit of $<1.52 \log \mathrm{cfu} /$ fruit in $45 \%$ of the samples; on the other hand, the number was above 4.0 $\log \mathrm{cfu} /$ fruit in $17.5 \%$ of the samples.

The rinse method was used to determine mould and yeast counts on the surface of whole fruits and to identify the moulds present on fruit surface. The surface of dried persimmon fruits had a mouldy appearance because of diffused sugar. In many studies, the rinse method was generally applied to determine microbial count of fruits and vegetables. In the present study, osmophilic counts and total mould and yeast counts were significantly higher in the rinse method compared with the homogenisation method $(P<0.05)$ (Figure 1$)$. In the rinse method, samples were taken from the entire surface of fruit, while in the homogenisation method, only $10 \mathrm{~g}$ of sample was taken for analysis. The rinse method is more appropriate for determining mycoflora in fruits.

According to statistical analysis, results show no significant difference between two sampling methods $(P>0.05)$ for osmophilic yeast count and separate counts of mould and yeasts. On the other hand, significant differences were observed by homogenisation and rinse methods for osmophilic mould counts $(P>0.05)$. Burnett and Beuchat (2001) indicate that the type of processing method, washing in peptone water, stomaching or homogenising, does not have significant influence on the number of Salmonella spp. recovered from raw fruits and vegetables.

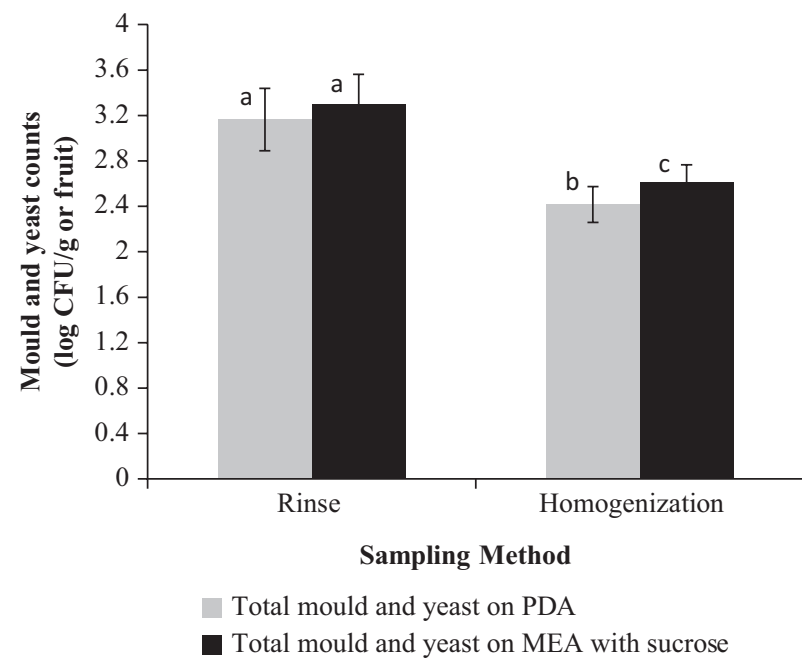

Figure 1. Mean values of yeast and mold counts of dried persimmon fruits obtained with different sampling methods using PDA or MEA with sucrose. Different letters indicate significant mean difference according to statistical analysis $(P<0.05)$. The error bars in the figures correspond to the mean standard errors.
Persimmon fruits were peeled and the mycoflora present on fruit surfaces was removed before the sun-drying process. Izumi et al. (2008a) obtained on average $4.1 \mathrm{log}$ $\mathrm{cfu} / \mathrm{g}$ of mould count in peeled persimmon fruits; on the other hand, mould count was below the detection limit of $<3 \mathrm{log}$ cfu/g for fruit flesh. Murakami et al. (2012) also indicated that mould counts of enzyme-peeled persimmon slices were below the detection limit of $3 \log \mathrm{cfu} / \mathrm{g}$. During the sun-drying process, drying fruits are re-contaminated with a variety of moulds and yeasts. Because of long drying periods of traditionally sun-dried foods, contaminated moulds produce mycotoxins by finding a growth medium. Microbial counts and diversity increase after coming in contact with plastic harvesting baskets and containers, which may be a source of contamination during harvesting. Therefore, to reduce microbial contamination in farms, agricultural water and harvesting equipment should focus on control points (Izumi et al., 2008b).

In the present study, it was observed that mycoflora of dried persimmon fruits contained 17 genera of mould at different contamination levels (Figure 2). The most common mould identified in dried persimmon fruits was Rhizopus spp., which has isolated from 28 of 40 samples (70\%). Rhizopus spp. is very common air contaminant found in most environments and possibly in processing plant areas (Tournas et al., 2006). Beside Rhizopus spp., the microflora of dried persimmon fruits mainly consisted of Penicillium spp. (40\%), Aspergillus spp. (22.5\%), Cladosporium spp. (15\%) and Alternaria spp. (10\%). Other mould genera which include Ulacladium spp., Chrysonilia spp., Endomyces spp., Chaetomium spp. and Paecilomyces spp. were isolated at a frequency of 5\%, while Moniella spp., Basipetrospora spp., Monascus spp., Mucor spp., Trichothecium spp., Byssochlamys spp. and Geotrichum spp. were isolated at a low frequency of $2.5 \%$ of dried persimmon fruits. Generally, microorganisms

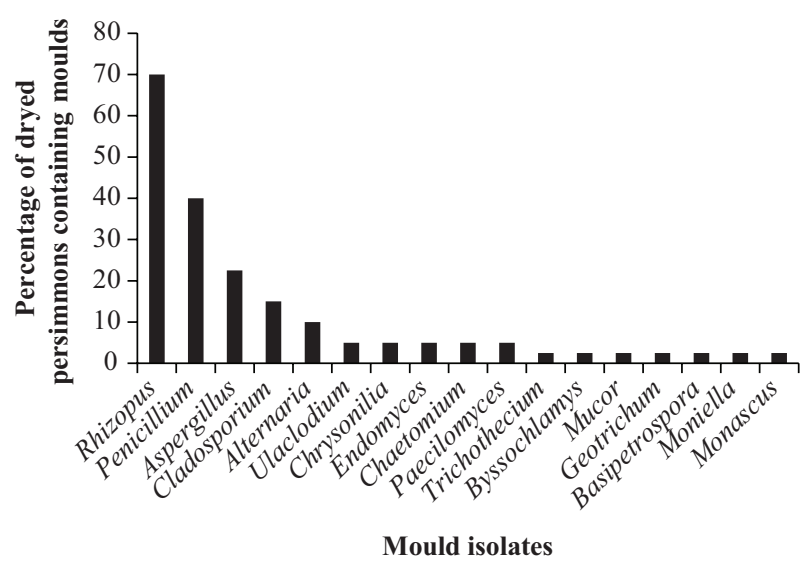

Figure 2. Frequency and distribution of moulds isolated from dried persimmon fruits. 
found at low frequencies are considered random contaminants (Tournas et al., 2006). High frequency of Penicillium spp., Aspergillus spp. and Alternaria spp. are a concern since these microorganisms are known to produce a wide spectrum of highly toxic metabolites. BokHee et al. (2012) reported that Penicillium spp., identified as a major causative microorganism, accounted for the highest percentage of contamination in dried persimmons. Cladosporium spp. and Aspergillus spp. were also isolated. Park et al. (2003) performed mycoflora detection of nine dried persimmon fruits. Identified mould proportions were found as: Alternaria 38\%, Aspergillus 2\%, Cladosporium 16\%, Fusarium 3\%, Mucor 4\%, Penicillium $2 \%$, Rhizopus $6 \%$ and unknown $29 \%$. There is little information about the mycobiota present on dried persimmon fruits. On the other hand, post-harvest diseases of fresh persimmon fruits were also studied. According to a previous study (Palou et al., 2015), Penicillium expansum, Cladosporium cladosporioides, Botrytis cinerea, Rhizopus spp. and Trichoderma spp. were the most frequently isolated fungi in fresh persimmon fruits. Aktaruzzaman et al. (2018) indicated that fungus B. cinerea was the causal agent of disease ('grey mould') found in fresh persimmon fruit. On the other hand, in our study, a low frequency of Botrytis spp. was isolated in dried persimmon fruits. It was indicated that the most frequent disease found in persimmons was alternaria black spot caused by Alternaria alternata. Other post-harvest pathogens such as P. expansum and C. cladosporioides were also isolated from infected persimmons after storage at $20-25{ }^{\circ} \mathrm{C}$ for up to 9 weeks (Palou et al., 2015).

In the present study, $95 \%$ of the samples were contaminated with moulds, and 17 different genera of moulds were isolated from dried persimmon fruits. Isolation of a wide range of mould genera increases the risk of presence of mycotoxins. Wang et al. (2018) found many types of mycotoxins, including Aflatoxin $\mathrm{B}_{2}$, Alternaria toxins, Ochratoxins (OTA, OTB) and Beauvericin (BEA) in dried persimmon fruits. Dried fruits are thought to be resistant to microbial spoilage because of their low water activity and moisture content, and high acidity and sugar content. Nevertheless, moulds are the most important microorganisms in dried fruits in terms of spoilage. Even if a small part of surface is infected by a mould, it may grow quickly within a short period. In addition, the number of infected fruits increases rapidly if the drying process is not performed correctly (Montville and Matthews, 2008; Vinson et al., 2008).

\section{Conclusions}

Mycological quality and the fungal profiles of dried persimmon fruits available in the market were evaluated. It was observed that dried persimmon fruits contained 17 different genera of moulds and $95 \%$ of the samples were contaminated with moulds and yeasts at different levels. For this reason, it is necessary to carry out the hurdle technique to prevent fungal growth that may occur during harvesting, processing and storage of the dried fruits. Our study shows that further research is needed to determine the mycotoxin production potential of isolates during the processing of persimmons.

\section{Conflict of interest}

The authors declare no conflicts of interest with respect to research, authorship and/or publication of this article.

\section{Funding}

This research received no specific grant from any funding agency in the public, commercial or not-for-profit sectors.

\section{Compliance with ethical standards}

This article followed all ethical standards for a research without direct contact with human or animal subjects.

\section{References}

Akbulut, M., Ercişli, S., Yıldırım, N., Orhan, E. and Agar, G., 2008. The comparison of persimmon genotypes (Diospyrus kaki Thunb.) by using RAPD and FAME data. Roumanian Biotechnological Letters 13: 3851-3858.

Aksoy, U., Eltem, R., Meyvaci, K.B., Altindisli, A. and Karabat, S., 2007. Five-year survey of ochratoxin A in processed sultanas from Turkey. Food Additives and Contaminants 24: 292-296. https:// doi.org/10.1080/02652030601039021

Aktaruzzaman, M., Lee, Y., Afroz, T. and Kim, B., 2018. The occurrence of postharvest gray-mold rot of sweet persimmon caused by Botrytiscinerea in Korea. European Journal of Plant Pathology 150: 245-251. https://doi.org/10.1007/s10658-017-1254-1

Battilani, P., Pietri, A., Bertuzzi, T., Languasco, L., Giorni, P. and Kozakiewicz, Z., 2003. Occurrence of ochratoxin A-producing fungi in grapes grown in Italy. Journal of Food Protection 66: 633-636. https://doi.org/10.4315/0362-028X-66.4.633

Bayman, P.I., Baker, J.L., Doster, M.A., Michailides, T.J. and Mahoney, N.E., 2002. Ochratoxin production by the Aspergillus ochraceus group and Aspergillus alliaceus. Applied Environmental Microbiology 68: 2326-2329. https://doi.org/10.1128/AEM.68. 5.2326-2329.2002

Beuchat, L.R., Komitopoulou, E., Beckers, H., Betts, R.P., Bourdichon, F., Fanning, S., Joosten, H.M. and Ter Kuile, B.H., 2013. Low-water activity foods: increased concern as vehicles of foodborne pathogens. Journal of Food Protection 76(1): 150-172. https://doi. org/10.4315/0362-028X.JFP-12-211

Bok-Hee, K., Mi-Young, J., Sang-Sun, H., Kee-Sun, S., Dong-Sun, L., Sang-Han, L., Jin-Man, L., 2012. Isolation and identification of contaminated organisms on dried persimmon. Korean Journal of Food Preservation 19(6): 939-945. https://doi.org/10.11002/ kjfp.2012.19.6.939 
Bourdoux, S., Li, D., Rajkovic, A., Devlieghere, F. and Uyttendaele, M., 2016. Performance of drying technologies to ensure microbial safety of dried fruits and vegetables. Comprehensive Reviews in Food Science and Food Safety 15(6): 1056-1066. https://doi. org/10.1111/1541-4337.12224

Burnett, A.B. and Beuchat, L.R., 2001. Comparison of sample preparation methods for recovering Salmonella from raw fruits, vegetables, and herbs. Journal of Food Protection 64: 1459-1465. https://doi.org/10.4315/0362-028X-64.10.1459

Chauhan, A.K.S. and Srivastava, K., 2009. Optimizing drying conditions for vacuum-assisted microwave drying of green peas (Pisum sativum L.). Drying Technology 27: 761-769. https://doi. org/10.1080/07373930902828120

Choi, J., Lee, H., Cho, J., Lee, Y., Woo, J. and Moon, K., 2017. Prediction of shelf-life andchanges in the quality characteristics of semidried persimmons stored at different temperatures. Food Science and Biotechnology 26(5): 1255-1262. https://doi. org/10.1007/s10068-017-0173-4.

Duan, X., Zhang, M., Mujumdar, A.S. and Wang, R., 2010. Trends in microwave-assisted freeze drying of foods. Drying Technology 28: 1-10. https://doi.org/10.1080/07373931003609666

Gardeli, C., Evageliou, V., Poulos, C., Yanniotis, S. and Komaitis, M., 2009. Drying of fennel plants: oven, freeze drying, effect of freeze-drying time, and use of biopolymers. Drying Technology 28: 542-549. https://doi.org/10.1080/07373931003622321

Gaziona, J.M. and Hennekens, C.H., 1993. The role of beta carotene in preventing of cardiovascular disease. In Canfield, L.M., Krinsky, N.J. and Olson, J.A. (eds.) Carotenoids in human health, New York Academy of Sciences, New York, pp. 127-138.

Harima, S., Nakano, R., Yamauchi, S., Kitano, Y., Yamamoto, Y., Inaba, A. and Kuba, Y., 2003. Extending shelf-life of astringent persimmon (Diospyros kaki Thunb.) fruit by 1-MCP. Postharvest Biology and Technology 29: 218-323. https://doi.org/10.1016/ S0925-5214(03)00058-9

Herry, M.P. and Lemetayer, N., 1992. Aflatoxin contamination in oil seeds, dried fruits and spices. Microbiologie Aliments Nutrition 10: 261-266.

Iamanaka, B.T., Menezes, H.C., Vicente, E., Leite, R.S.F. and Taniwaki, M.H., 2007. A flat oxigenic fungi and aflatoxins occurrence in sultanas and dried figs commercialized in Brazil. Food Control 18(5): 454-457. https://doi.org/10.1016/j.foodcont.2005.12.002

Izumi, H., Hisa, K. and Murakami, Y., 2008a. Sanitation and microbiological quality in production field and fruit-packing shed of persimmon and Satsuma mandarin in Japan. Microbiology Insights 1: 25-40. https://doi.org/10.4137/MBI.S868

Izumi, H., Tsukada, Y., Poubol, J. and Hisa, K., 2008b. On-farm sources of microbial contamination of persimmon fruit in Japan. Journal of Food Protection 71(1): 52-59.

MacDonald, S., Wilson, P., Barnes, K., Damant, A., Massey, R., Mortby, E. and Shepherd, M.J., 1999. Ochratoxin A in dried vine fruit: method development and survey. Food Additives and Contaminants 16: 253-260. https://doi.org/10.1080/026520399284019

Marques, L.G., Silveira, A.M. and Freire, J.T., 2006. Freeze-drying characteristics of tropical fruits. Drying Technology 24: 457-463. https://doi.org/10.1080/07373930600611919
Matthews-Roth, M.M., 1993. Carotenoids in erythropoietic proporphyria and other photosensitivity diseases. In Canfield, L.M., Krinsky N.J. and Olson, J.A. (eds.) Carotenoids in human health, New York Academy of Sciences, New York, pp. 148-155.

Meyvaci, K.B., Altindisli, A., Aksoy, U., Eltem, R., Turgut, H., Arasiler, Z. and Kartal, N., 2005. Ochratoxin A in sultanas from Turkey I: survey of unprocessed sultanas from vineyards and packing-houses. Food Additives and Contaminants 22: 1138-1143. https://doi.org/10.1080/02652030500199132

Möller, T.E. and Nyberg, M., 2003. Ochratoxin A in raisins and currants: basic extraction procedure used in two small marketing surveys of the occurrence and control of the heterogeneity of the toxins in samples. Food Additives and Contaminants 20: 1072-1076. https://doi.org/10.1080/02652030310001615212

Montville, T.J. and Matthews, K.R., 2008. Food Microbiology an introduction. 2nd edition. ASM Press, Washington, DC, USA, pp. 295-296.

Murakami, Y., Ozaki, Y. and Izumi, H., 2012. Microbiological and physicochemical quality of enzymatically peeled persimmon fruit for fresh-cut slices. Hort Science 47(3): 382-385. https://doi. org/10.21273/HORTSCI.47.3.382

Nicoleti, J.F., Silveira, V., Tlis-Romero, J. and Telis, V.R.N., 2007. Influence of drying conditions on ascorbic acid during convective drying of whole persimmons. Drying Technology 25: 891-899. https://doi.org/10.1080/07373930701370365

Palou, L., Montesinos-Herrero, C., Tarazona, I., Besada, C. and Taberner, V., 2015. Incidence and etiology of postharvest fungal diseases of persimmon (Diospyros kaki Thunb. cv. Rojo Brillante) in Spain. Plant Disease 99: 1416-1425. https://doi.org/10.1094/ PDIS-01-15-0112-RE

Park, J.W., Shon, D.H. and Kim, Y.B., 2003. Application of an enzymelinked immunosorbent assay for detecting mold contamination in agricultural commodities and comparison with conventional assays. Food and Agricultural Immunology 15(3-4): 159-166. https://doi.org/10.1080/09540100400013393

Pitt, J.I. and Hocking, A.D., 2009. Fungi and food spoilage. 3rd edition. Springer, New York, NY, USA.

Plaza, L., Colina, C., Ancos, B., Sanchez-Moreno, C. and Cano, M.P., 2012. Influence of ripening and astringency on carotenoid content of high-pressure treated persimmon fruit (Diospyros kaki L.). Food Chemistry 130: 591-597. https://doi.org/10.1016/j. foodchem.2011.07.080

Prakash, P.Y. and Bhargava, K., 2016. A modified micro chamber agar spot slide culture technique for microscopic examination of filamentous fungi. Journal of Microbiological Methods 123: 126-129. https://doi.org/10.1016/j.mimet.2016.02.015

Rahman, M.S., Al-Shamsi, Q.H., Bengtsson, G.B., Sablani, S.S. and Al-Alawi, A., 2009. Drying kinetics and allicin potential in garlic slices during different methods of drying. Drying Technology 27(3): 467-477. https://doi.org/10.1080/07373930802683781

Sablani, S.S., 2006. Drying of fruits and vegetables: retention of nutritional/functional quality. Drying Technology 24: 123-135. https://doi.org/10.1080/07373930600558904.

Skaar, I. and Stenwig, H., 1996. Salt-yeast extract-sucrose agar, a suitable medium for enumeration and isolation of fungi from silage. Applied and Environmental Microbiology 62: 3614-3619. 


\section{G.T. Gündüz et al.}

Tee, E.S., 1992. Carotenoids and retionoids in human nutrition Critical Reviews in Food Science and Nutrition 31: 103-163. https://doi.org/10.1080/10408399209527563

Tournas, V.H., Katsoudas, E. and Miracco, E.J., 2006. Moulds, yeasts and aerobic plate counts in ginseng supplements. International Journal of Food Microbiology 108(2): 178-181. https://doi. org/10.1016/j.ijfoodmicro.2005.11.009

Tous, J. and Ferguson, L., 1996. Mediterranean fruits. In Janick, J. (eds.) Progress in new crops. ASHD Press, Arlington, VA, p. 416.

Turkish Food Codex, 2011. Regulation on Turkish Food Codex, Microbiological Criteria. Official Gazette of Publication: 29.12.2011-28157, Ankara, Turkey.
Vinson, J.A., Zubik, L., Bose, P., Samman, N. and Proch, J., 2008. Dried fruits: excellent in vitro and in vivo antioxidants. Journal of the American College of Nutrition 24: 44-50. https://doi.org/10. 1080/07315724.2005.10719442

Wang, Y., Nie, J., Yan, Z., Li, Z., Cheng, Y. and Chang, W., 2018. Occurrence and co-occurrence of mycotoxins in nuts and dried fruits from China. Food Control 88: 181-189. https://doi. org/10.1016/j.foodcont.2018.01.013

Zohri, A.A. and Abdel-Gawad, K.M., 1993. Survey of microflora and mycotoxins of some dried fruits in Egypt. Journal of Basic Microbiology 33: 279-288. https://doi.org/10.1002/ jobm.36203304.13 